\title{
Phenanthrene Antibiotic Targets Bacterial Membranes and Kills Staphylococcus aureus With a Low Propensity for Resistance Development
}

\author{
Bo-Chen Chen ${ }^{1 t}$, Chang-Xin Lin't, Ni-Pi Chen ${ }^{1}$, Cheng-Xian Gao', Ying-Jie Zhao ${ }^{2}$ and \\ Chao-Dong Qian ${ }^{1 *}$ \\ ${ }^{1}$ Institute of Molecular Medicine, College of Life Science, Zhejiang Chinese Medical University, Hangzhou, China, ${ }^{2}$ College \\ of Pharmaceutical Science, Zhejiang Chinese Medical University, Hangzhou, China
}

\section{OPEN ACCESS}

Edited by: Santi M. Mandal,

Indian Institute of Technology Kharagpur, India

Reviewed by:

Gourisankar Roymahapatra, Haldia Institute of Technology, India Sandeep Sharma, University of Pennsylvania, United States

*Correspondence: Chao-Dong Qian zzdqcd@163.com

tThese authors have contributed equally to this work.

Specialty section: This article was submitted to Antimicrobials, Resistance and Chemotherapy,

a section of the journal Frontiers in Microbiology

Received: 08 April 2018 Accepted: 26 June 2018 Published: 17 July 2018

Citation:

Chen B-C, Lin C-X, Chen N-P. Gao C-X, Zhao Y-J and Qian C-D (2018) Phenanthrene Antibiotic

Targets Bacterial Membranes and Kills Staphylococcus aureus With a Low Propensity for Resistance Development.

Front. Microbiol. 9:1593. doi: 10.3389/fmicb.2018.01593
New classes of antibiotics with different mechanisms of action are urgently required for combating antimicrobial resistance. Blestriacin, a dihydro-biphenanthrene with significant antibacterial activity, was recently isolated from the fibrous roots of Bletilla striata. Here, we report the further characterization of the antimicrobial potential and mode of action of blestriacin. The phenanthrene compound inhibited the growth of all tested clinical isolates of Staphylococcus aureus including methicillin-resistant S. aureus (MRSA). The minimum inhibitory concentrations (MICs) of blestriacin against these pathogens ranged from 2 to $8 \mu \mathrm{g} / \mathrm{mL}$. Minimum bactericidal concentration (MBC) tests were conducted, and the results demonstrated that blestriacin was bactericidal against $S$. aureus. This effect was confirmed by the time-kill assays. At bactericidal concentrations, blestriacin caused loss of membrane potential in B. subtilis and $S$. aureus and disrupted the bacterial membrane integrity of the two strains. The spontaneous mutation frequency of $S$. aureus to blestriacin was determined to be lower than $10^{-9}$. The selection and whole genome sequencing of the blestriacin resistant mutants of $S$. aureus indicated that the development of blestriacin resistance in S. aureus involves mutations in multi-genes. All these observations can be rationalized by the suggestion that membrane is a biological target of blestriacin.

Keywords: dihydro-biphenanthrene, natural product, antibiotic, mode of action, bactericidal effect, membranedamaging activity, Staphylococcus aureus

\section{INTRODUCTION}

Staphylococcus aureus is an opportunistic pathogen causing a wide range of hospital- and community-acquired infections with high morbidity (Archer, 1998; Al-Mebairik et al., 2016) Diseases caused by the Gram-positive bacterium range from skin infections to life-threatening illnesses, such as septicemia, pneumonia, endocarditis, meningitis, and catheter-related infections due to biofilm formation (Al-Mebairik et al., 2016; Hogan et al., 2016; Ahn et al., 2018). S. aureus is also a leading cause of staphylococcal food poisoning because it can produce a wide variety of toxins including staphylococcal enterotoxins and staphylococcal-like proteins (Le et al., 2003; 
Argudín et al., 2010). The disease caused by S. aureus is a worldwide public health issue (Kadariya et al., 2014; Al-Mebairik et al., 2016), and the situation is exacerbated by the emergence of drug-resistant strains, particularly the methicillin-resistant S. aureus (MRSA) (Wendlandt et al., 2013; Foster, 2017). Some success has been achieved in the discovery and development of various drugs for the treatment of infections caused by antibioticresistant pathogens (Stevens et al., 2004; Ziglam, 2007; Abbas et al., 2017).

Plant-derived antimicrobial agents have received much attention due to their effectiveness against drug-resistant strains, and diverse antimicrobial activities including suppression of virulence factors, antibiofilm activity, anti-persister activity and inhibition of efflux pumps in pathogens (Borges et al., 2015; Mukherjee et al., 2016; Barbieri et al., 2017; Khan et al., 2017). Thousands of phytochemicals have been reported as antibacterial compounds and belong to different classes, such as alkaloids, terpenoids, polyphenols, tannins, and phenanthrenes. Among of them, phenanthrenes are a relatively uncommon class of aromatic metabolites in the plant kingdom, and are mainly found in the Orchidaceae and Juncaceae (Kovács et al., 2008; Tóth et al., 2018). As typical phytoalexins of these plants, phenanthrenes have been shown to possess antimicrobial activities against various pathogens including drug-resistant strains (Kovács et al., 2008; Tang et al., 2008; Yoshikawa et al., 2014; Qian et al., 2015; Tóth et al., 2018). Correspondingly, some phenanthrene-containing plants have been used in traditional medicine for the treatment of infectious diseases (Sun et al., 2010; Namukobe et al., 2011, 2014).

Bletilla striata (Reichb. f.), a precious medicinal plant, has been used in traditional medicine for the treatment of pneumorrhagia and pneumonophthisis (Sun et al., 2010). Early investigations on the chemical constituents of plant revealed the presence of mono phenanthrenes, dimeric phenanthrenes, and their derivatives (Qian et al., 2015; Guo et al., 2016). The contents of mono phenanthrenes have been found to be higher than those of dimeric phenanthrenes in B. striata, although dimers generally have significantly stronger antibacterial activity than the monomers. During a recently screening program of antimicrobial phytochemicals, we found four new $9^{\prime}, 10^{\prime}$-dihydro-biphenanthrenes from the medicinal plant (Qian et al., 2015). One of them, 4,7,4'-trimethoxy-9',10'dihydro(1,1'-biphenanthrene)-2,2' $7^{\prime}$-triol, named as blestriacin (Figure 1), exhibits significant antibacterial activity against all tested Gram-positive bacteria including MRSA with MICs of 2-4 $\mu \mathrm{g} / \mathrm{mL}$.

Although the antimicrobial activity of phenanthrenes is well documented, their mode of action has not been reported. In this work, we use blestriacin as a tool compound to investigate the antibacterial mechanism of phenanthrenes through a combination of approaches, including minimum inhibitory concentration (MIC)/minimum bactericidal concentration (MBC) determination, time-killing assay, growth kinetics analysis, membrane potential estimation, membrane integrity measurement, and genome sequencing analysis.

\section{MATERIALS AND METHODS}

\section{Bacterial Strains and Materials}

Staphylococcus aureus ATCC 29213, S. aureus ATCC 43300, and Enterococcus faecalis ATCC 29212 were purchased from the American Type Culture Collection. Bacillus subtilis 168 was a gift from Mei-Ya Li (Zhejiang Chinese Medical University, Hangzhou, China). Clinical isolates were obtained from patients at the Shaoxing Central Hospital, Shaoxing, China. All bacterial strains used for the activity assay were grown routinely at $37^{\circ} \mathrm{C}$ on Mueller-Hinton (MH) agar/broth.

Blestriacin was isolated and purified from the fibrous roots of $B$. striata according to the method described previously (Qian et al., 2015). The purity of the compound was determined with HPLC and found to be $>95 \%$. The rhizomes of B. striata were collected from Tuankou Town, Zhejiang Province, China, and authenticated by Professor ZS Ding. A voucher specimen was deposited in Zhejiang Chinese Medical University with specimen number BS-2012-I. Nisin was purchased from SigmaAldrich (St. Louis, MO, United States), and other antibiotics were obtained from Shanghai Yuanye Bio-Technology Co. (Shanghai, China). Propidium iodide (PI) and bis-(1,3-dibutylbarbituric acid) trimethine oxonol $\left[\mathrm{DiBAC}_{4}(3)\right]$ were purchased from $\mathrm{BD}$ Biosciences (San Diego, CA, United States) and Enzo Life Sciences (Farmingdale, NY, United States), respectively.

\section{Determination of MIC and MBC}

The MIC of the antimicrobial agents in 96-well microtiter plates was determined by using the broth microdilution method (Guo et al., 2016). Bacteria were seeded at $5 \times 10^{5}$ cells per well in a 96well plate containing $\mathrm{MH}$ broth with varying concentrations of each test sample. Vancomycin, erythromycin, and oxacillin were used as positive controls. Blestriacin was dissolved in dimethyl sulfoxide (DMSO). Sterile MH broth containing 5\% DMSO was used as negative control. MBC was determined by subculturing $0.1 \mathrm{~mL}$ from each well showing no visible sign of growth in the $\mathrm{MH}$ agar. The MIC was defined as the lowest concentration of drug which inhibited visible growth after incubation at $37^{\circ} \mathrm{C}$ for $20 \mathrm{~h}$, and the MBC was defined as the lowest compound concentration resulting in $\mathrm{a} \geq 3$ - $\log$ reduction in the number of $\mathrm{CFU}$ after incubation for $24 \mathrm{~h}$ at $37^{\circ} \mathrm{C}$ (Guo et al., 2016).

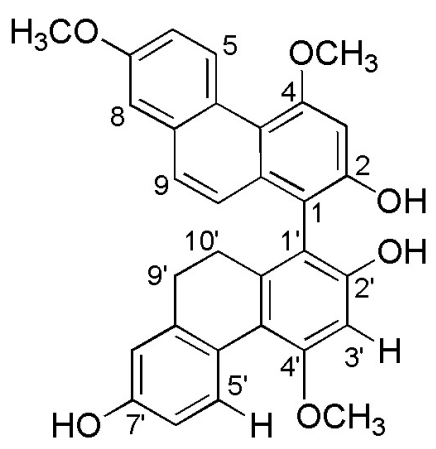

FIGURE 1 | Structure of blestriacin. 


\section{Time-Kill Assay}

The time-kill kinetics of blestriacin was determined for four S. aureus strains as previously reported (Guo et al., 2016). Briefly, the antimicrobial agent was added to a logarithmic-phase broth culture of approximately $10^{6} \mathrm{CFU} / \mathrm{mL}$ to yield concentrations of $1 \times$ MIC, $2 \times$ MIC, and $4 \times$ MIC. The same volume of DMSO was added to the control tube. The culture was incubated at $37^{\circ} \mathrm{C}$ with shaking for $24 \mathrm{~h}$. One hundred microliter aliquots were removed from each test tube after $0,0.5,1,3,6$, and 24 h of incubation, and serially diluted (1:10) with cold saline. The appropriate dilutions $(100 \mu \mathrm{L})$ were then spotted on $\mathrm{MH}$ agar plates $(5 \mu \mathrm{L}$ per spot), and viable bacteria were quantitated after $24 \mathrm{~h}$ of incubation at $37^{\circ} \mathrm{C}$. Results were obtained from three independent experiments presented as the average \pm standard deviation (SD).

\section{Growth Kinetics Analysis}

Overnight cultures of Bacillus subtillis 168 were grown in $\mathrm{MH}$ broth at $37^{\circ} \mathrm{C}$ to an OD600 of 0.3 . The bacteria were then diluted one-fold in pre-warmed $\mathrm{MH}$ broth containing $4 \times$ the MIC of the indicated antimicrobial agents. Bacterial growth was monitored by measuring optical density at $600 \mathrm{~nm}$ (OD600nm) with a microplate spectrophotometer (Multiscan MK3, Thermo Labsystems).

\section{Determination of Membrane Potential and Integrity}

The effects of blestriacin on the potential of bacterial membrane was tested by flow cytometry with a fluorescent probe $\mathrm{DiBAC}_{4}(3)$ (Bos et al., 2012). The cells of B. subtilis 168 and S. aureus 29213 were grown in $\mathrm{MH}$ broth to an OD600 of 0.5 and diluted twice with sterilized saline water. After incubation with an antimicrobial agent at $4 \times \mathrm{MIC}$ for specified time at $37^{\circ} \mathrm{C}$, the cells were harvested by centrifugation at $8000 \mathrm{rpm}$ for $5 \mathrm{~min}$ and washed twice with sterile saline. The resulting pellets were resuspended in normal saline to approximately $10^{6} \mathrm{CFU} / \mathrm{mL}$. The cells were then stained for $30 \mathrm{~min}$ at $37^{\circ} \mathrm{C}$ with $60 \mu \mathrm{L}$ of $\mathrm{DIBAC}_{4}(3)$. Fluorescence was measure with an Accuri C6 flow cytometer (BD Biosciences) with excitation and emission wavelengths of 485 and $520 \mathrm{~nm}$, respectively.

Membrane integrity assays were performed in the same manner as the method described above, except that the fluorescent dye PI was added to a final concentration of $30 \mu \mathrm{M}$ instead of $\mathrm{DiBAC}_{4}(3)$. Flow cytometric data were collected with the Accuri C6 flow cytometer with excitation at $490 \mathrm{~nm}$ and emission collected at $635 \mathrm{~nm}$. Nisin was used as a positive control for membrane damage and vancomycin as a negative control. The reported results were obtained from three independent cultures.

\section{Scanning Electron Microscopy (SEM)}

For the electron microscopy analysis, overnight cultures of bacteria grown in $\mathrm{MH}$ broth was collected by centrifugation $\left(6000 \mathrm{rpm}\right.$ for $5 \mathrm{~min}$ at $4^{\circ} \mathrm{C}$ ) and washed three times with sterilized saline water. Bacterial cells present in the suspension containing $10^{8} \mathrm{CFU} / \mathrm{mL}$ were incubated with or without blestriacin $(32 \mu \mathrm{g} / \mathrm{mL})$ for $3 \mathrm{~h}$. After incubation, the bacterial suspension was again centrifuged and washed three
TABLE 1 | MICs of blestriacin against clinical isolates of Staphylococcus aureus.

\begin{tabular}{lcccc}
\hline Indicator strain & \multicolumn{4}{c}{ MIC $(\boldsymbol{\mu g} / \mathbf{m L})$} \\
\cline { 2 - 4 } & Blestriacin & Vancomycin & Erythromycin & Oxacillin \\
\hline S. aureus 3211 & 2 & 1 & $>4$ & $>4$ \\
S. aureus 3304 & 2 & 0.5 & $>4$ & $>4$ \\
S. aureus 0001 & 8 & 1 & $>4$ & $>4$ \\
S. aureus 0002 & 2 & 1 & $>4$ & $>4$ \\
S. aureus 0003 & 4 & 1 & $\leq 0.5$ & $\leq 0.25$ \\
S. aureus 0004 & 4 & 2 & $>4$ & $>4$ \\
S. aureus 0005 & 2 & 1 & $\leq 0.5$ & $\leq 0.25$ \\
S. aureus 0006 & 2 & 1 & $\leq 0.5$ & $\leq 0.25$ \\
S. aureus 0007 & 2 & 1 & $\leq 0.5$ & $\leq 0.25$ \\
S. aureus 0008 & 2 & 1 & $>4$ & $>4$ \\
S. aureus 0009 & 2 & 1 & $\leq 0.5$ & $\leq 0.25$ \\
S. aureus 0010 & 2 & 1 & $\leq 0.5$ & $\leq 0.25$ \\
S. aureus 0011 & 2 & 1 & $\leq 0.5$ & $\leq 0.25$ \\
S. aureus & 2 & 1 & 0.5 & 0.125 \\
ATCC 29213 & & & &
\end{tabular}

TABLE 2 | MBCs of blestriacin against Staphylococcus aureus and Enterococcus faecalis.

\begin{tabular}{|c|c|c|c|}
\hline Strain and compound & MIC $(\mu \mathrm{g} / \mathrm{mL})$ & $M B C(\mu \mathrm{g} / \mathrm{mL})$ & MBC/MIC \\
\hline \multicolumn{4}{|c|}{ S. aureus ATCC 29213 (MSSA) } \\
\hline Blestriacin & 2 & 4 & 2 \\
\hline Vancomycin & 1 & 2 & 2 \\
\hline \multicolumn{4}{|c|}{ S. aureus ATCC 43300 (MRSA) } \\
\hline Blestriacin & 2 & 2 & 1 \\
\hline Vancomycin & 2 & 2 & 1 \\
\hline \multicolumn{4}{|l|}{ S. aureus 3211 (MRSA) } \\
\hline Blestriacin & 2 & 2 & 1 \\
\hline Vancomycin & 1 & 2 & 2 \\
\hline \multicolumn{4}{|l|}{ S. aureus 3304 (MRSA) } \\
\hline Blestriacin & 2 & 2 & 1 \\
\hline Vancomycin & 2 & 2 & 1 \\
\hline \multicolumn{4}{|l|}{ E. faecalis ATCC 29212} \\
\hline Blestriacin & 2 & 2 & 1 \\
\hline Vancomycin & 2 & $>8$ & $>4$ \\
\hline
\end{tabular}

times with sterilized saline water. A thin smear of bacterial suspension was prepared on a glass slide, air-dried, and fixed with $2.5 \%$ glutaraldehyde in phosphate-buffered saline (PBS, $0.1 \mathrm{~mol} / \mathrm{L}, \mathrm{pH} 7.0$ ) at $4^{\circ} \mathrm{C}$ overnight. The sample was washed three times with PBS and post-fixed in 1\% osmium tetroxide for $20 \mathrm{~min}$, followed by dehydration in gradually increased concentration of ethanol ranging from 50 to $100 \%$ (10 $\mathrm{min}$ in each stage). The samples were then serially dehydrated in 50, 75,90 , and $100 \%$ tert-butanol solutions, followed by vacuum freeze drying for $1 \mathrm{~h}$ with a $\mathrm{t}-\mathrm{BuOH}$ freeze dryer (VFD21S, Vacuum Device Inc., Japan). The dried cells were coated with gold using a sputter coater (Hitachi E-1010, Japan), and observed under a scanning electron microscope (Hitachi SU8000, Japan). 


\section{S. aureus ATCC 29213}

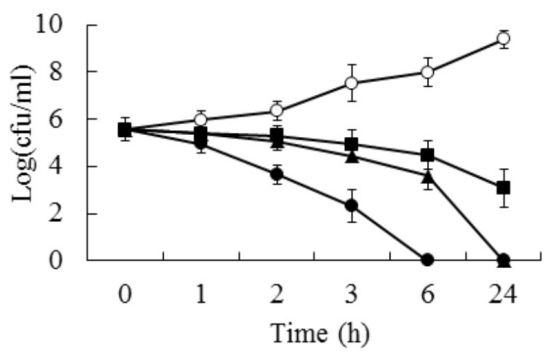

S. aureus 3211

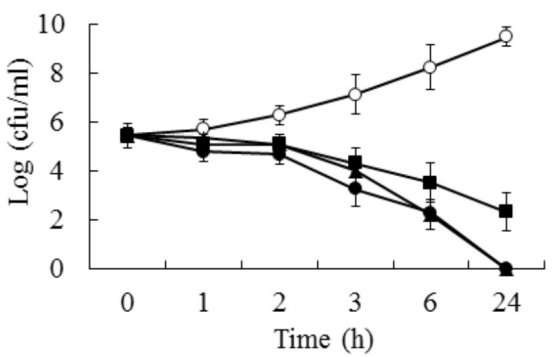

S. aureus ATCC 43300

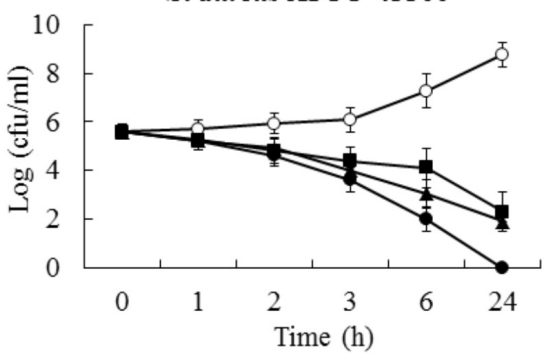

S. aureus 3304

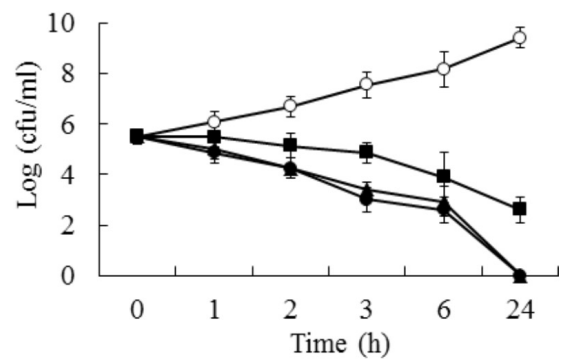

$4 \times \mathrm{MIC}$

FIGURE 2 | Time-kill curves for Staphylococcus aureus treated with different concentrations of blestriacin. The curves are viable cell concentrations plotted against time. Open circles, nondrug control; closed squares, $1 \times$ MIC of blestriacin; closed triangles, $2 \times \mathrm{MIC}$ of blestriacin; closed circles, $4 \times \mathrm{MIC}$ of blestriacin. MIC,

minimum inhibitory concentration. Data represent the mean $\pm \mathrm{SD}(n=3)$.

\section{Isolation and Analysis of Spontaneous Resistant Mutants}

An inoculum of $3 \times 10^{10} \mathrm{CFU} / \mathrm{mL}$ of $S$. aureus was spread onto $\mathrm{MH}$ plates containing different concentrations of blestriacin. All plates were incubated at $37^{\circ} \mathrm{C}$ overnight and examined after $48 \mathrm{~h}$. Mutational frequency was determined as previously described (Kaul et al., 2013). Individual colonies resistant to blestriacin were isolated and purified from $\mathrm{MH}$ agar containing the same blestriacin concentration. The MICs of mutants were confirmed by the broth microdilution method as described above.

\section{Whole Genome Sequencing and Assembly}

Wild type $S$. aureus 43300 (Sa01) together with its drugresistant mutants $\mathrm{Sa} 02$ and $\mathrm{Sa} 03$ were subjected to genomic DNA isolation with a ZR Fungal/Bacterial Genomic DNA Extraction Kit (Zymo Research Corp., Orange, CA, United States). Genome sequencing was performed by Sangon Biotech (Shanghai, China). An Illumina MiSeq platform with $2 \times 150$-bp reads was used for the sequencing. The reads were trimmed, quality-filtered and then assembled by using SPAdes software (Bankevich et al., 2012). BWA/SAMtools (Li et al., 2009; Li and Durbin, 2010) were used for alignment of raw reads and single nucleotide polymorphism (SNP) detection. SNP presented in both mutant strains was confirmed by PCR and Sanger dideoxy-terminator sequencing. Mutations were compared with a reference genome of $S$. aureus MRSA252 (genome NC_002952.2). Sequence similarities were investigated by using the BLAST server at the National Center for Biotechnology Information $\left(\mathrm{NCBI}^{1}\right)$ site. This Whole Genome Shotgun projects have been deposited at DDBJ/ENA/GenBank under the accessions: Sa01 QAJW00000000; Sa02 QAJX00000000; Sa03 QAJY00000000. The version described in this paper is version QAJW 01000000, QAJX01000000, QAJY01000000, respectively.

\section{RESULTS}

\section{Clinical Isolates of S. aureus Are Highly Susceptible to Blestriacin}

Blestriacin exhibits significantly anti-Gram-positive bacterial activity against $S$. aureus, Staphylococcus epidermidis, E. faecalis, and B. subtilis (Qian et al., 2015). To further evaluate the effect of blestriacin against $S$. aureus, we determined the MICs of the 13 clinical isolates consisting of methicillin-resistant (MRSA) and sensitive (MSSA) S. aureus using a microbroth dilution method. Consistent with previous study (Qian et al., 2015), blestriacin was active against most of the tested clinical isolates with the MICs ranging from 2 to $4 \mu \mathrm{g} / \mathrm{mL}$, whether the isolate is a methicillinresistant strain (MICs of Oxacillin $>4 \mu \mathrm{g} / \mathrm{mL}$ ) (Table 1).

\section{Blestriacin Is a Bactericidal Agent}

Minimum bactericidal concentration test showed that blestriacin exerted bactericidal effect upon $S$. aureus strains with the $\mathrm{MBC} / \mathrm{MIC}$ ratios of 1-2 (Table 2). Interestingly, blestriacin had

\footnotetext{
${ }^{1}$ http://www.ncbi.nlm.nih.gov/BLAST/
} 


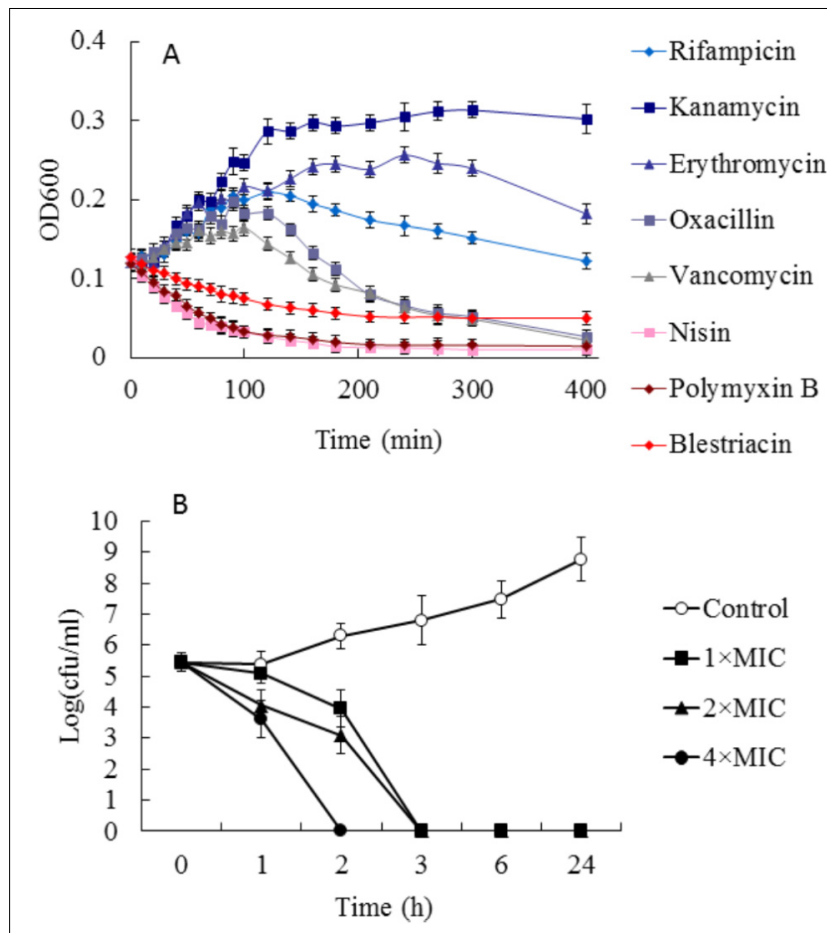

FIGURE 3 | Effect of blestriacin on Bacillus subtilis 168. (A) Growth kinetics of B. subtilis 168 exposed to blestriacin or various antibiotics with known mechanisms of action. Four times the minimal inhibitory concentration (MIC) of the respective compounds were used. (B) Killing kinetics of blestriacin against $B$. subtilis 168. Open circles, nondrug control; closed squares, $1 \times$ MIC of blestriacin; closed triangles, $2 \times$ MIC of blestriacin; closed circles, $4 \times \mathrm{MIC}$ of blestriacin. The MIC of blestriacin against $B$. subtilis 168 is $2 \mu \mathrm{g} / \mathrm{mL}$. All experiments were performed in triplicate, and analysis data are presented as the mean $\pm \mathrm{SD}$.

a MBC/MIC ratio of 1 against E. faecalis ATCC 29212, while vancomycin yielded $\mathrm{MBC} / \mathrm{MIC}$ ratios of $>4$ against the same strain. To further examine the bactericidal activities of blestriacin against $S$. aureus, we performed killing experiments against two standard strains and two clinical isolates. As shown in Figure 2, blestriacin was bactericidal in a dose-dependent manner. No living cell was detected at $24 \mathrm{~h}$ for all tested strains treated with $4 \times$ the MIC of blestriacin, which is consistent with the bactericidal behavior revealed by the $\mathrm{MBC} / \mathrm{MIC}$ analysis described above.

\section{Blestriacin Disrupts Membrane Potential and Integrity}

To preliminarily investigate the possible mechanism of antimicrobial action of blestriacin, we determined the growth kinetics of $B$. subtilis 168 exposed to blestriacin or various antibiotics with known mechanisms of action (Schneider et al., 2010). The results (Figure 3A) demonstrated that blestriacin exhibited kinetic behavior similar to rapidly lytic membraneactive agents (such as polymyxin and nisin) but not to cell wall-interfering agents (such as vancomycin, oxacillin) or antibiotics with transcription (rifampicin), or protein synthesis (kanamycin, erythromycin) as its primary target. Consistently with this, the bacteria killing of blestriacin for B. subtilis 168 was rapid at the concentration of $4 \times \mathrm{MIC}$, and no living cell was detected within $120 \mathrm{~min}$ (Figure 3B). Thus, the effect of blestriacin on membrane potential and integrity was investigated.

The ability of blestriacin to induce membrane depolarization was evaluated by using the fluorescent dye $\operatorname{DiBAC}_{4}(3)$, which can enter depolarized membranes and exhibit increased green fluorescence due to its binding to lipid-rich intracellular components (Alam et al., 2015). As expected, the addition of blestriacin or nisin to $B$. subtilis 168 suspensions caused a drastic in fluorescence, indicating that the agent was capable of disrupting the membrane potential of B. subtilis (Figure 4A). By contrast, the negative-control vancomycin did not alter the membrane potential. The effect of blestriacin on the membrane integrity of B. subtilis 168 was monitored using a PI fluorescent probe, which is an indicator of disturbance of plasmatic membrane integrity. Fluorescence measurement showed that blestriacin caused membrane damage of $B$. subtilis 168 , which was evident by a great increase in the red fluorescence of cells.

The capability of blestriacin to disrupt membrane potential and integrity of S. aureus 29213 was also determined. As shown in Figure 4B, when $S$. aureus was treated with blestriacin for $3 \mathrm{~h}$, a drastic increase in fluorescence of $\mathrm{DiBAC}_{4}(3)$ and PI were both observed compared with the untreated cultures. Interestingly, incubation of S. aureus 29213 with $4 \times$ MIC of blestriacin for $2 \mathrm{~h}$ leads to a weak increase in fluorescence, while incubation of $B$. subtilis 168 with the same concentration of blestriacin for only $0.5 \mathrm{~h}$ leads to a great increase in fluorescence of both dyes (data not shown). These results indicated that the membrane of B. subtilis 168 is more vulnerable than that of S. aureus 29213 to blestriacin.

To investigate the effects of blestriacin on cell morphology of bacteria, scanning electron microscopic analysis were carried out. As shown in Figure 5A, untreated $S$. aureus had smooth and intact morphology. In contrast, numerous lysed cells accompanied by cellular debris were observed in the bacteria treated with blestriacin (Figure 5B). Similarly, the antimicrobial agent also induced dramatic morphological changes and structure disruption of B. subtillus cells (Figures 5C,D).

\section{Blestriacin Kills S. aureus With a Low Spontaneous Resistance Mutation Frequency}

To determine the spontaneous resistance mutation frequency of S. aureus against blestriacin, we plated S. aureus ATCC 29213 at $10^{10} \mathrm{CFU}$ onto $\mathrm{MH}$ agar containing $4 \times$, and $8 \times \mathrm{MICs}$ of blestriacin. No mutant of strain 29213 resistant to blestriacin was observed even when plating on media was conducted with a low dose $(4 \times \mathrm{MIC})$ of the compound. Then we carried out a study with $S$. aureus ATCC 43300. Blestriacin -resistant $S$. aureus were obtained only by growing the strain on $\mathrm{MH}$ agar plates containing blestriacin at $4 \times \mathrm{MIC}$. The resistance frequency was determined to be about $2 \times 10^{-9}$. Broth MIC determination of blestriacin -resistant $S$. aureus strains showed twofold increase compared to wild-type bacteria. Interestingly, blestriacin -resistant mutants also exhibited reduced (two-fold) 
A

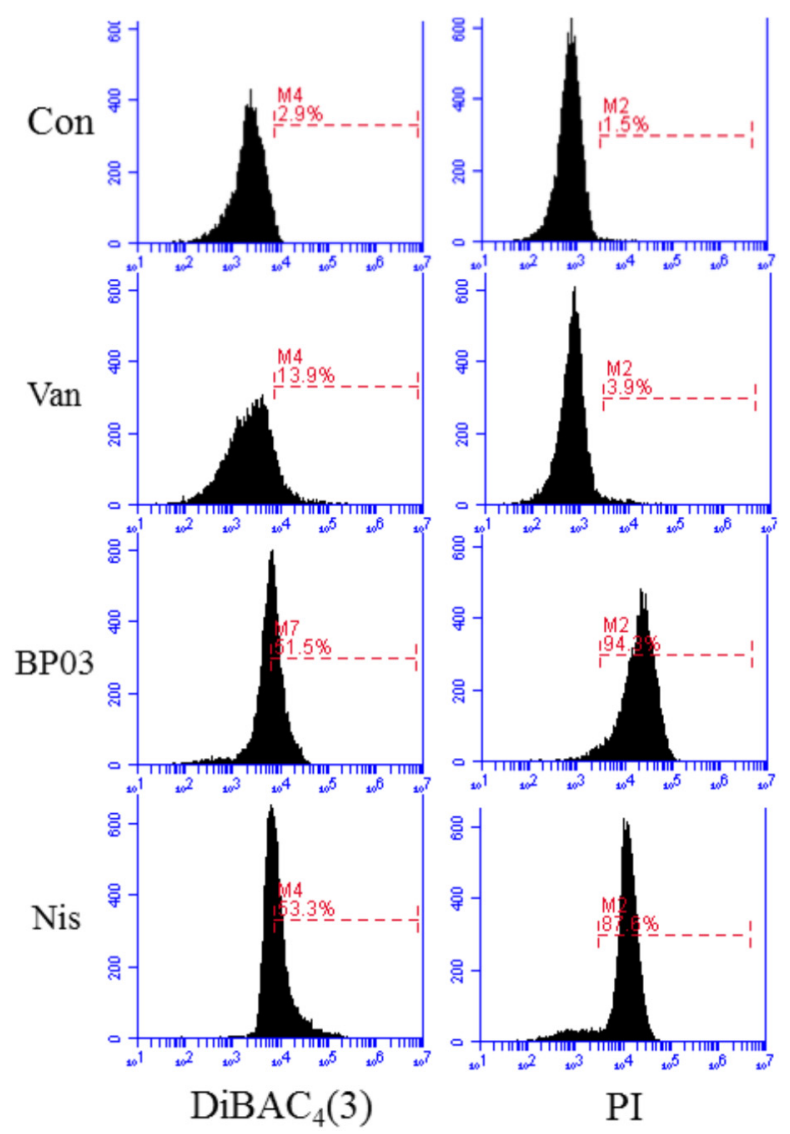

B

S. aureus ATCC 29213

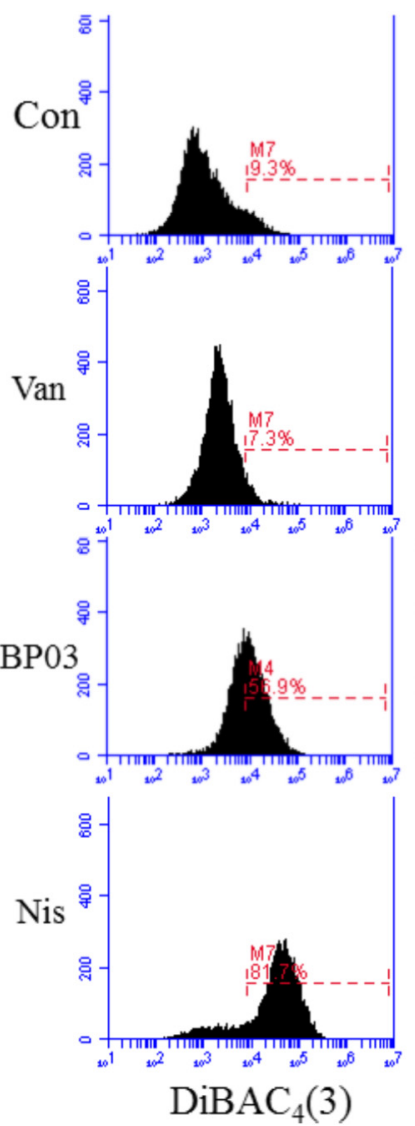

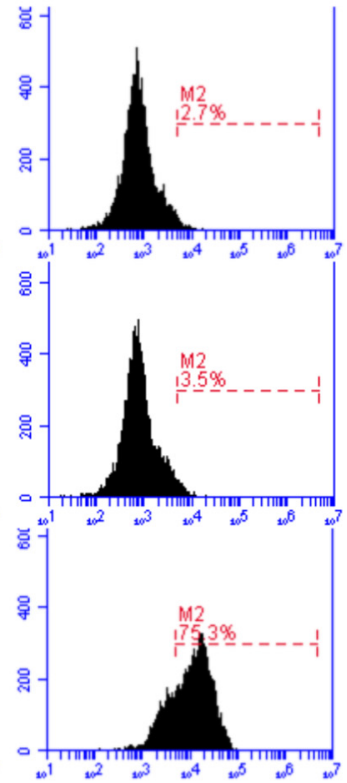

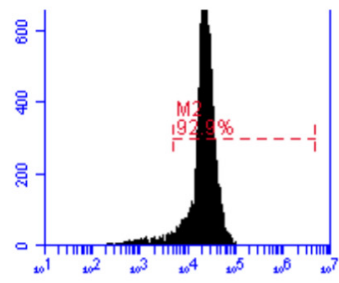

PI

FIGURE 4 | The effect of blestriacin on membrane potential and integrity of B. subtilis 168 (A) and S. aureus ATCC 29213 (B). Representative data from three independent cultures of both strains are shown following exposure to antimicrobial agents at $4 \times$ MIC for 2 h, except the incubation time of S. aureus ATCC 29213 with blestriacin was $3 \mathrm{~h}$. Vancomycin was used as a negative control and nisin was used as a positive control. Con, no-drug treated control; Van, vancomycin $(4 \mu \mathrm{g} / \mathrm{mL})$; Nis, nisin $(20 \mu \mathrm{g} / \mathrm{mL})$. BP03, blestriacin.

susceptibility to nisin, but showed no changes in sensitivity toward vancomycin and kanamycin.

\section{Blestriacin Resistance in S. aureus Is Associated With Mutations in Multi-Genes}

To gain insight into the genetic bases of blestriacin resistance in S. aureus ATCC 43300, we isolated and sequenced the genomic DNAs of two independently selected blestriacin resistant strains ( $\mathrm{Sa} 02$ and $\mathrm{Sa} 03$ ) and parent strain. No significantly change in the growth rates of the two mutants were observed, except the twofold increase in the MIC compared to wild-type $S$. aureus. Whole-genome sequencing revealed six common single-nucleotide polymorphisms in the two mutants, including five nonsynonymous substitutions and one synonymous substitution in coding regions of the genomes (Table 3).

The $\mathrm{Sa} 02$ and $\mathrm{Sa03}$ strains harbored the substitution Arg48Ser in a locus tag, SAR2257, which is annotated as a putative transport protein involved in multidrug resistance
(Holden et al., 2004). The locus SAR2257 contains a frameshift after codon 114 in $S$. aureus MRSA252 reference strain but not in the parent and mutant strains of S. aureus ATCC 43300. Four additional nonsynonymous SNPs were identified in open reading frames predicted to encode maltose $\mathrm{ABC}$ transporter, oxidoreductase, aspartate aminotransferase and transcriptional regulator. Maltose $\mathrm{ABC}$ transporter and oxidoreductase seem to be related to the transport and metabolism of sugars, while aspartate aminotransferase and transcriptional regulator are probably related to the metabolism of amino acids and nitrate regulation, respectively.

\section{DISCUSSION}

In this study, the antibacterial properties of blestriacin, a dihydrobiphenanthrene isolated from the fibrous roots of $B$. striata were investigated. Blestriacin exhibited potent bactericidal activity against $S$. aureus, including MRSA. Several other phenanthrenes from B. striata and other plants have also been reported to possess antimicrobial activity against a wide range of pathogens 


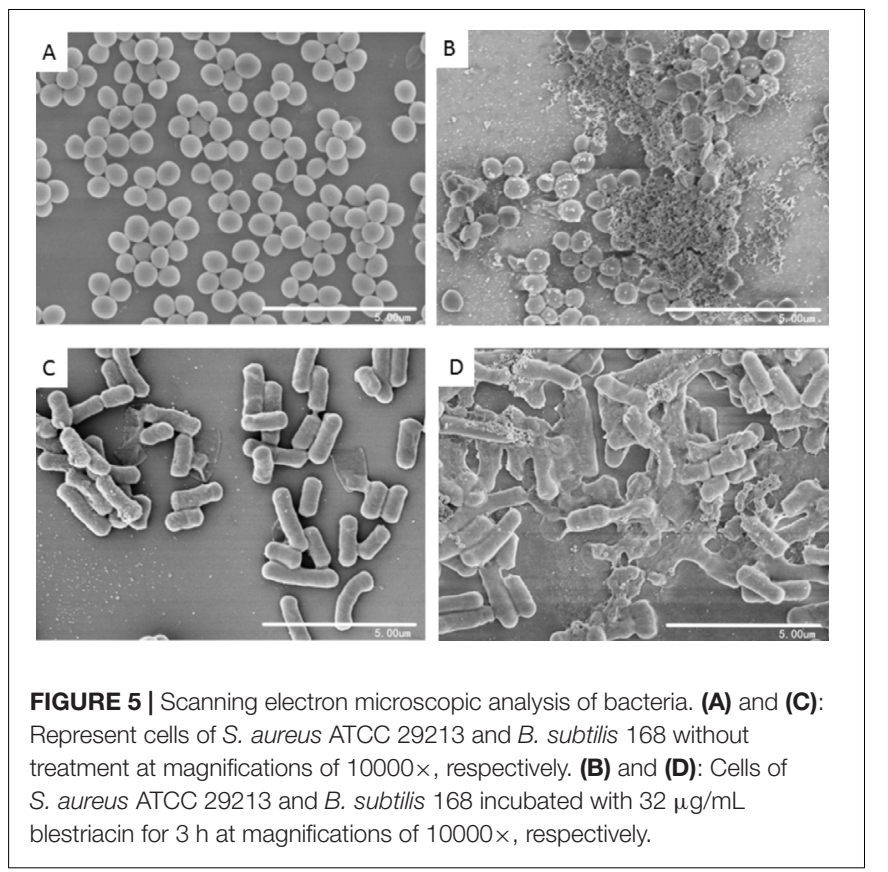

(Takagi et al., 1983; Kovács et al., 2008; Qian et al., 2015). However, most of their MICs exceeded $10 \mu \mathrm{g} / \mathrm{mL}$. On the basis of the MIC values, which are below $10 \mu \mathrm{g} / \mathrm{mL}$ for the natural compound against $S$. aureus and other Gram-positive bacteria, blestriacin is regarded as an effective antibacterial agent and deserves more attention (Rios and Recio, 2005; Radulovic et al., 2013).

Although phenanthrenes have been studied as antimicrobial agents since the 1980s (Takagi et al., 1983), the mechanism of the action of these compounds has not been investigated. Growth kinetic measurements of B. subtilis 168 exposed to various antibiotics showed that blestriacin exhibited kinetic behavior similar to polymyxin and nisin, suggesting blestriacin is a membrane-damaging agent. To test whether blestriacin is a cytoplasmic membrane disruptive agent, we investigated the effect of the compound on membrane potential and integrity. As expected, blestriacin disrupted the bacterial membrane integrity of $B$. subtilis and S. aureus, and this was accompanied with the dissipation of membrane potential in two test strains. Consistent with the observation that the bactericidal speed of blestriacin to $B$. subtilis was faster than that of $S$. aureus, the membrane of $B$. subtilis is more vulnerable than that of $S$. aureus against blestriacin. The correlation between the time dependence of antibiotic activity and the effects on membrane integrity further confirmed that blestriacin kills bacterial cells by damaging their cytoplasmic membranes. Consistent with these results, SEM images showed that both bacteria exposed to blestriacin had severely damaged morphology (Figure 5).

Pathogens can evolve to acquire resistance to nearly all antibiotics, which is widely associated with treatment failure. The spontaneous mutation rate of bacteria to an antibiotic is closely related to the mechanism of action of a drug used. It
TABLE 3 | Nucleotide mutations presented in both mutant strains (SaO2 and $\mathrm{SaO3}$ ) of S. aureus ATCC 43300 compared to the wide-type strain.

\begin{tabular}{|c|c|c|c|c|}
\hline SNP & $\begin{array}{l}\text { Nucleotide } \\
\text { change }\end{array}$ & $\begin{array}{l}\text { Predicted } \\
\text { amino } \\
\text { change }\end{array}$ & $\begin{array}{l}\text { S. aureus } \\
\text { MRSA252 } \\
\text { Locus tag }\end{array}$ & $\begin{array}{l}\text { Predicted gene } \\
\text { product }\end{array}$ \\
\hline 1 & $\mathrm{~T} \rightarrow \mathrm{G}$ & N207K & SAR0206 & $\begin{array}{l}\text { Maltose ABC } \\
\text { transporter } \\
\text { substrate-binding } \\
\text { protein (Puyet and } \\
\text { Espinosa, 1993) }\end{array}$ \\
\hline 2 & $A \rightarrow G$ & $\mathrm{~T} 111 \mathrm{~A}$ & SAR0210 & $\begin{array}{l}\text { gfo/ldh/MocA family } \\
\text { oxidoreductase } \\
\text { (Kanagasundaram and } \\
\text { Scopes, 1992) }\end{array}$ \\
\hline 3 & $\mathrm{~A} \rightarrow \mathrm{T}$ & K225I & SAR2028 & $\begin{array}{l}\text { Aspartate } \\
\text { aminotransferase } \\
\text { (Okamoto et al., 1996) }\end{array}$ \\
\hline 4 & $\mathrm{~T} \rightarrow \mathrm{A}$ & R48S & SAR2257 & $\begin{array}{l}\text { Putative multidrug efflux } \\
\text { transporter }\end{array}$ \\
\hline 5 & $\mathrm{C} \rightarrow \mathrm{A}$ & A30S & SAR2480 & $\begin{array}{l}\text { Transcriptional regulator } \\
\text { (Msadek et al., 1990) }\end{array}$ \\
\hline 6 & $\mathrm{~A} \rightarrow \mathrm{T}$ & V301V & SAR2589 & MFS transporter \\
\hline
\end{tabular}

is reported that the development of resistance is less frequent for several membrane-active agents than for other antibiotics (Silverman et al., 2001; Hurdle et al., 2011). The spontaneous mutation frequency of $S$. aureus to blestriacin was determined to be $2 \times 10^{-9}$ or less, which is consistent with the finding that blestriacin is a membrane-targeted agent.

Genetic characterization of in vitro-derived mutants resistant to an antibacterial agent can provide information about the mechanism of antibiotic resistance as well as the mode of action of this active compound. Whole-genome sequencing of blestriacin -resistant mutants ( $\mathrm{Sa} 02$ and $\mathrm{Sa} 03$ ) of S. aureus and their parent revealed nonsynonymous single nucleotide variants in five open reading frames. One of these genes encoded a putative transporter (SAR2257). Further inspection revealed that the putative protein was similar to the QacA/EmrB multidrug resistance efflux pumps, which were response regulators of twocomponent systems. The pump QacA conferred resistance to quaternar ammonium cations from S. aureus (Rouch et al., 1990), and EmrB protects Escherchia coil from uncouplers (Lomovskaya and Lewis, 1992). A unique feature of emr consisting of $e m r A$ and $e m r B$ is that it seems to confer resistance only to fairly hydrophobic compounds. As blestriacin is a natural phenanthrene with extremely low water solubility, we hypothesized that the putative transporter (SAR2257) is likely to participate in blestriacin efflux from bacterial membranes. However, how the putative transporter participates in blestriacin resistance requires further investigation.

Four additional nonsynonymous SNPs were identified in both mutant strains. Although the role of these mutations is less clear and the predicted functions of these genes seem to be not directly associated with drug resistance, their role in the development of blestriacin resistance in $S$. aureus cannot be ruled out. These gene mutations may help bacteria to better adapt to stress through changes in cell metabolism and transport that optimize the global cellular response to antimicrobial agent exposures. It was recently 
reported that daptomycin resistance in E. faecalis was associated with mutations in eight genes (Tran et al., 2013).

\section{CONCLUSION}

Overall, our findings demonstrate that blestriacin, a natural phenanthrene, is a unique bactericidal antibiotic. It has a membrane-damaging activity and low propensity to select or induce resistance in $S$. aureus. The development of blestriacin resistance in $S$. aureus involves mutations in multi-genes, which is unlike those agents act upon one target and for which a single point mutation can confer significant resistance. All these observations are consistent with the finding that blestriacin acts as a membrane-damaging antibiotic.

\section{REFERENCES}

Abbas, M., Paul, M., and Huttner, A. (2017). New and improved? A review of novel antibiotics for Gram-positive bacteria. Clin. Microbiol. Infect. 23, 697-703. doi: 10.1016/j.cmi.2017.06.010

Ahn, K. B., Baik, J. E., Yun, C. H., and Han, S. H. (2018). Lipoteichoic acid inhibits Staphylococcus aureus biofilm formation. Front. Microbiol. 9:327. doi: 10.3389/fmicb.2018.00327

Alam, M. Z., Wu, X., Mascio, C., Chesnel, L., and Hurdle, J. G. (2015). Mode of action and bactericidal properties of surotomycin against growing and nongrowing Clostridium difficile. Antimicrob. Agents Chemother. 59, 5165-5170. doi: 10.1128/AAC.01087-15

Al-Mebairik, N. F., El-Kersh, T. A., Al-Sheikh, Y. A., and Marie, M. A. M. (2016). A review of virulence factors, pathogenesis, and antibiotic resistance in Staphylococcus aureus. Rev. Med. Microbiol. 27, 50-56. doi: 10.1097/MRM. 0000000000000067

Archer, G. L. (1998). Staphylococcus aureus: a well-armed pathogen. Clin. Infect. Dis. 26, 1179-1181. doi: 10.1086/520289

Argudín, M. Á, Mendoza, M. C., and Rodicio, M. R. (2010). Food poisoning and Staphylococcus aureus enterotoxins. Toxins 2, 1751-1773. doi: 10.3390/ toxins 2071751

Bankevich, A., Nurk, S., Antipov, D., Gurevich, A. A., Dvorkin, M., Kulikov, A. S., et al. (2012). SPAdes: A new genome assembly algorithm and its applications to single-cell sequencing. J. Comp. Biol. 19, 455-477. doi: 10.1089/cmb.2012.0021

Barbieri, R., Coppo, E., Marchese, A., Daglia, M., Sobarzo-Sánchez, E., Nabavi, S. F., et al. (2017). Phytochemicals for human disease: an update on plantderived compounds antibacterial activity. Microbiol. Res. 196, 44-68. doi: 10. 1016/j.micres.2016.12.003

Borges, A., Saavedra, M. J., and Simões, M. (2015). Insights on antimicrobial resistance, biofilms and the use of phytochemicals as new antimicrobial agents. Curr. Med. Chem. 22, 2590-2614. doi: 10.2174/0929867322666150530210522

Bos, J., Yakhnina, A. A., and Gitai, Z. (2012). BapE DNA endonuclease induces an apoptotic-like response to DNA damage in Caulobacter. Proc. Natl. Acad. Sci. U.S.A. 109, 18096-18101. doi: 10.1073/pnas.1213332109

Foster, T. J. (2017). Antibiotic resistance in Staphylococcus aureus. Current status and future prospects. FEMS Microbiol. Rev. 41, 430-449. doi: 10.1093/femsre/ fux007

Guo, J. J., Dai, B. L., Chen, N. P., Jin, L. X., Jiang, F. S., Ding, Z. S., et al. (2016). The anti-Staphylococcus aureus activity of the phenanthrene fraction from fibrous roots of Bletilla striata. BMC Complement. Altern. Med. 16:491. doi: 10.1186/s12906-016-1488-z

Hogan, S., Zapotoczna, M., Stevens, N. T., Humphreys, H., O'Gara, J. P., and O'Neill, E. (2016). Eradication of Staphylococcus aureus catheter-related biofilm infections using ML:8 and Citrox. Antimicrob. Agents Chemother. 60, 5968-5975. doi: 10.1128/AAC.00910-16

Holden, M. T., Feil, E. J., Lindsay, J. A., Peacock, S. J., Day, N. P., Enright, M. C., et al. (2004). Complete genomes of two clinical Staphylococcus aureus strains:

\section{AUTHOR CONTRIBUTIONS}

C-DQ designed and wrote the manuscript. B-CC, C-XL, N-PC, and Y-JZ performed the experiments and analyzed the data. $\mathrm{C}-\mathrm{XG}$ provided critical comments on the manuscript.

\section{FUNDING}

This study was supported by Zhejiang Provincial Public Welfare Technology Research and Social Development Project of China (2016C33087), Zhejiang Medical and Health Science and Technology Plan Project (2017KY498), Special Research Funds of Zhejiang Chinese Medical University (2016ZG15), and Xinmiao talents Project of Zhejiang Province (2017R410042), China.

evidence for the rapid evolution of virulence and drug resistance. Proc. Natl. Acad. Sci. U.S.A. 101, 9786-9791. doi: 10.1073/pnas.0402521101

Hurdle, J. G., O’Neill, A. J., Chopra, I., and Lee, R. E. (2011). Targeting bacterial membrane function: an underexploited mechanism for treating persistent infections. Nat. Rev. Microbiol. 9, 62-75. doi: 10.1038/nrmicro2474

Kadariya, J., Smith, T. C., and Thapaliya, D. (2014). Staphylococcus aureus and staphylococcal food-borne disease: an ongoing challenge in public health. Biomed Res. Int. 2014:827965. doi: 10.1155/2014/827965

Kanagasundaram, V., and Scopes, R. K. (1992). Cloning, sequence analysis, and expression of the structural gene encoding glucose-fructose oxidoreductase from Zymomonas mobilis. J. Bacteriol. 174, 1439-1447.

Kaul, M., Mark, L., Zhang, Y., Parhi, A. K., LaVoie, E. J., and Pilch, D. S. (2013). An FtsZ-targeting prodrug with oral antistaphylococcal efficacy in vivo. Antimicrob. Agents Chemother. 57, 5860-5869. doi: 10.1128/AAC.01016-13

Khan, I., Bahuguna, A., Kumar, P., Bajpai, V. K., and Kang, S. C. (2017). Antimicrobial potential of carvacrol against uropathogenic Escherichia coli via membrane disruption, depolarization, and reactive oxygen species generation. Front. Microbiol. 8:2421. doi: 10.3389/fmicb.2017.02421

Kovács, A., Vasas, A., and Hohmann, J. (2008). Natural phenanthrenes and their biological activity. Phytochemistry 69, 1084-1110. doi: 10.1016/j.phytochem. 2007.12.005

Le, L. Y., Baron, F., and Gautier, M. (2003). Staphylococcus aureus and food poisoning. Genet. Mol. Res. 2, 63-76.

Li, H., and Durbin, R. (2010). Fast and accurate long-read alignment with BurrowsWheeler transform. Bioinformatics 26, 589-595. doi: 10.1093/bioinformatics/ btp698

Li, H., Handsaker, B., Wysoker, A., Fennell, T., Ruan, J., Homer, N., et al. (2009). The sequence alignment/map format and SAMtools. Bioinformatics 25, 2078-2079. doi: 10.1093/bioinformatics/btp352

Lomovskaya, O., and Lewis, K. (1992). Emr, an Escherichia coli locus for multidrug resistance. Proc. Natl. Acad. Sci. U.S.A. 89, 8938-8942.

Msadek, T., Kunst, F., Henner, D., Klier, A., Rapoport, G., and Dedonder, R. (1990). Signal transduction pathway controlling synthesis of a class of degradative enzymes in Bacillus subtilis: expression of the regulatory genes and analysis of mutations in degS and degU. J. Bacteriol. 172, 824-834.

Mukherjee, D., Zou, H., Liu, S., Beuerman, R., and Dick, T. (2016). Membranetargeting AM-0016 kills mycobacterial persisters and shows low propensity for resistance development. Future Microbiol. 11, 643-650. doi: 10.2217/fmb-20 15-0015

Namukobe, J., Kasenene, J. M., Kiremire, B. T., Byamukama, R., KamatenesiMugisha, M., Krief, S., et al. (2011). Traditional plants used for medicinal purposes by local communities around the Northern sector of Kibale National Park, Uganda. J. Ethnopharmacol. 136, 236-245. doi: 10.1016/j.jep.2011. 04.044

Namukobe, J., Kiremire, B. T., Byamukama, R., Dumontet, V., Guéritte, F., Krief, S., et al. (2014). Cycloartane triterpenes from the leaves of Neoboutonia macrocalyx L. Phytochemistry 102, 189-196. doi: 10.1016/j.phytochem.2014.02 
Okamoto, A., Kato, R., Masui, R., Yamagishi, A., Oshima, T., and Kuramitsu, S. (1996). An aspartate aminotransferase from an extremely thermophilic bacterium, Thermus thermophilus HB8. J. Biochem. 119, 135-144.

Puyet, A., and Espinosa, M. (1993). Structure of the maltodextrin-uptake locus of Streptococcus pneumoniae. Correlation to the Escherichia coli maltose regulon. J. Mol. Biol. 230, 800-811. doi: 10.1006/jmbi.1993.1202

Qian, C. D., Jiang, F. S., Yu, H. S., Fu, Y. H., Cheng, D. Q., Gan, L. S., et al. (2015). Antibacterial Biphenanthrenes from the fibrous roots of Bletilla striata. J. Nat. Prod. 78, 939-943. doi: 10.1021/np501012n

Radulovic, N. S., Blagojevic, P. D., Stojanovic-Radic, Z. Z., and Stojanovic, N. M. (2013). Antimicrobial plant metabolites: structural diversity and mechanism of action. Curr. Med. Chem. 20, 932-952. doi: 10.2174/09298671380 5219136

Rios, J., and Recio, M. (2005). Medicinal plants and antimicrobial activity. J. Ethnopharmacol. 100, 80-84. doi: 10.1016/j.jep.2005.04.025

Rouch, D. A., Cram, D. S., DiBerardino, D., Littlejohn, T. G., and Skurray, R. A. (1990). Efflux-mediated antiseptic resistance gene qacA from Staphylococcus aureus: common ancestry with tetracycline- and sugar-transport proteins. Mol. Microbiol. 4, 2051-2062. doi: 10.1111/j.1365-2958.1990.tb00565.x

Schneider, T., Kruse, T., Wimmer, R., Wiedemann, I., Sass, V., Pag, U., et al. (2010). Plectasin, a fungal defensin, targets the bacterial cell wall precursor Lipid II. Science 328, 1168-1172. doi: 10.1126/science.1185723

Silverman, J. A., Oliver, N., Andrew, T., and Li, T. (2001). Resistance studies with daptomycin. Antimicrob. Agents Chemother. 45, 1799-1802.

Stevens, D. L., Dotter, B., and Madaras-Kelly, K. (2004). A review of linezolid: the first oxazolidinone antibiotic. Expert Rev. Anti Infect. Ther. 2, 51-59. doi: 10.1586/14787210.2.1.51

Sun, L. L., Yang, Y. H., Liu, J. K., Cheng, W. F., and Zhou, M. (2010). Studies on botanical origin of Bletilla striata and its textual research herb textual research. J. Chin. Med. Mater. 33, 1965-1968.

Takagi, S., Yamaki, M., and Inoue, K. (1983). Antimicrobial agents from Bletilla striata. Phytochemistry 22, 1011-1015.
Tang, G. H., Zhang, Y., Gu, Y. C., Li, S. F., Di, Y. T., Wang, Y. H., et al. (2008). Trigoflavidols A-C, degraded diterpenoids with antimicrobial activity, from Trigonostemon flavidus. J. Nat. Prod. 71, 1414-1417. doi: 10.1021/np3001128

Tóth, B., Hohmann, J., and Vasas, A. (2018). Phenanthrenes: a promising group of plant secondary metabolites. J. Nat. Prod 81, 661-678. doi: 10.1021/acs. jnatprod.7b00619

Tran, T. T., Panesso, D., Gao, H., Roh, J. H., Munita, J. M., Reyes, J., et al. (2013). Whole-genome analysis of a daptomycin-susceptible enterococcus faecium strain and its daptomycin-resistant variant arising during therapy. Antimicrob. Agents Chemother. 57, 261-268. doi: 10.1128/AAC.01454-12

Wendlandt, S., Schwarz, S., and Silley, P. (2013). Methicillin-resistant Staphylococcus aureus: A food-borne pathogen? Annu. Rev. Food Sci. Technol. 4, 117-139. doi: 10.1146/annurev-food-030212-182653

Yoshikawa, K., Baba, C., Iseki, K., Ito, T., Asakawa, Y., Kawano, S., et al. (2014). Phenanthrene and phenylpropanoid constituents from the roots of Cymbidium Great Flower 'Marylaurencin' and their antimicrobial activity. J. Nat. Med. 68, 743-747. doi: 10.1007/s11418-014-0854-8

Ziglam, H. (2007). Daptomycin and tigecycline: a review of clinical efficacy in the antimicrobial era. Expert Opin. Pharmacother. 8, 2279-2292. doi: 10.1517/ 14656566.8.14.2279

Conflict of Interest Statement: The authors declare that the research was conducted in the absence of any commercial or financial relationships that could be construed as a potential conflict of interest.

Copyright (C) 2018 Chen, Lin, Chen, Gao, Zhao and Qian. This is an open-access article distributed under the terms of the Creative Commons Attribution License (CC BY). The use, distribution or reproduction in other forums is permitted, provided the original author(s) and the copyright owner(s) are credited and that the original publication in this journal is cited, in accordance with accepted academic practice. No use, distribution or reproduction is permitted which does not comply with these terms. 